\title{
CuH-Catalyzed Regio- and Enantioselective Hydrocarboxylation of Allenes: Towards Carboxylic Acids with Acyclic Quaternary Centers
}

\author{
Sheng Feng and Stephen L. Buchwald*
}

\begin{abstract}
We report a method to prepare $\alpha$-chiral carboxylic acid derivatives, including those bearing all-carbon quaternary centers, through an enantioselective CuH-catalyzed hydrocarboxylation of allenes with a commercially available fluoroformate. A broad range of heterocycles and functional groups on the allenes were tolerated in this protocol, giving enantioenriched $\alpha$ quaternary and tertiary carboxylic acid derivatives in good yields with exclusive branched regioselectivity. The synthetic utility of this approach was further demonstrated by derivatization of the products to afford biologically important compounds, including the antiplatelet drug indobufen.
\end{abstract}

All-carbon quaternary stereocenters, a structural feature that can impart significant chemical and biological impact to a molecule, are critical to many synthetic and medicinal applications. ${ }^{1}$ Consequently, catalytic and enantioselective approaches for constructing all-carbon quaternary centers, especially functionalized stereocenters, are highly desirable. ${ }^{2}$ Carboxylic acids, a chemically versatile functional group, that can bear an $\alpha$-stereogenic center often serve as useful synthetic intermediates. ${ }^{3}$ More importantly, $\alpha$-chiral carboxylic acid derivatives themselves constitute an essential class of compounds in pharmaceutical, agrochemical, and natural product arenas (Figure 1A). ${ }^{4}$ Methods for generating enantioenriched $\alpha$-chiral carboxylic acids have long been sought after. ${ }^{5}$ Prominent synthetic strategies targeting $\alpha$-chiral carboxylic acids or esters via asymmetric catalysis include hydrogenation of $\alpha, \beta$ unsaturated carboxylic acids, ${ }^{6}$ carbene-induced $\mathrm{C}-\mathrm{H}$ insertion with diazoacetates, ${ }^{7}$ enantioselective protonation ${ }^{8}$ or hydrogen atom transfer ${ }^{9}$ processes, and $\alpha$-functionalization of carboxylic acid derivatives. ${ }^{10-12}$ Nonetheless, catalytic access ${ }^{13}$ to enantioenriched acyclic carboxylic acids or esters featuring an allcarbon $\alpha$-quaternary stereocenter remains challenging. ${ }^{2 a-b}$ In this regard, common synthetic methods include allylic alkylation of geometrically pure alkenes, ${ }^{14}$ often with superstoichiometric organometallic reagents, and $\alpha$-functionalization of carboxylic acid derivatives, ${ }^{11,12 \mathrm{f}}$ which typically necessitates a $\beta$-directing group or electron-withdrawing group (Figure 1B).

As an alternative, the hydrocarboxylation ${ }^{15,16}$ of prochiral unsaturated substrates represents a straightforward approach for preparing carboxylic acids. Asymmetric hydrocarboxylation has typically ${ }^{17}$ been achieved through palladium-catalyzed hydroxy- and alkoxycarbonylation processes using $\mathrm{CO}$ gas or a carbon monoxide surrogate. ${ }^{18,19}$ Despite significant advances in this area, the vast majority of the methods can only synthesize $\alpha$-tertiary acids or esters from vinyl arenes, and a highly enantioselective technique for the assembly of $\alpha$-quaternary carboxylic acids through a hydrocarboxylation or hydroesterification of unsaturated substrates is still unknown. ${ }^{17 a}$

Based upon our research program in copper hydride $(\mathrm{CuH})$ catalyzed asymmetric hydrofunctionalization of unsaturated substrates, ${ }^{20}$ we sought to develop a hydrocarboxylation method for constructing enantioenriched carboxylic acids, especial- ly $\alpha$-quaternary acids. Specifically, we envisioned that a chiral organocopper species, generated in situ from the hydrocupration of an unsaturated substrate, could engage a suitable carboxylation reagent to afford enantioenriched carboxylic acids. Previously, when $\mathrm{CO}_{2}$ was used as an electrophile in $\mathrm{CuH}-$ catalyzed olefin hydrofunctionalization reactions, the initiallyformed silylated carboxylic acid intermediates underwent facile reduction and led to the formation of hydroxymethylene products. $^{21}$ To circumvent this reduction pathway, we targeted the $\mathrm{CuH}$-catalyzed hydroesterification, as the products are unreactive under the reaction conditions and can be readily hydrolyzed to give the corresponding carboxylic acids. An ester directly attached to a leaving group is proposed as the electrophile for realizing the hydrocarboxylation process (Figure $1 \mathrm{~B})$. In order to obtain $\alpha$-quaternary esters and acids, we sought to perform a regioselective hydrocarboxylation of allenes as the unsaturated substrate. Herein, we report a highly enantioselective $\mathrm{CuH}$-catalyzed hydrocarboxylation to furnish both $\alpha$-quaternary and tertiary carboxylic acid derivatives.

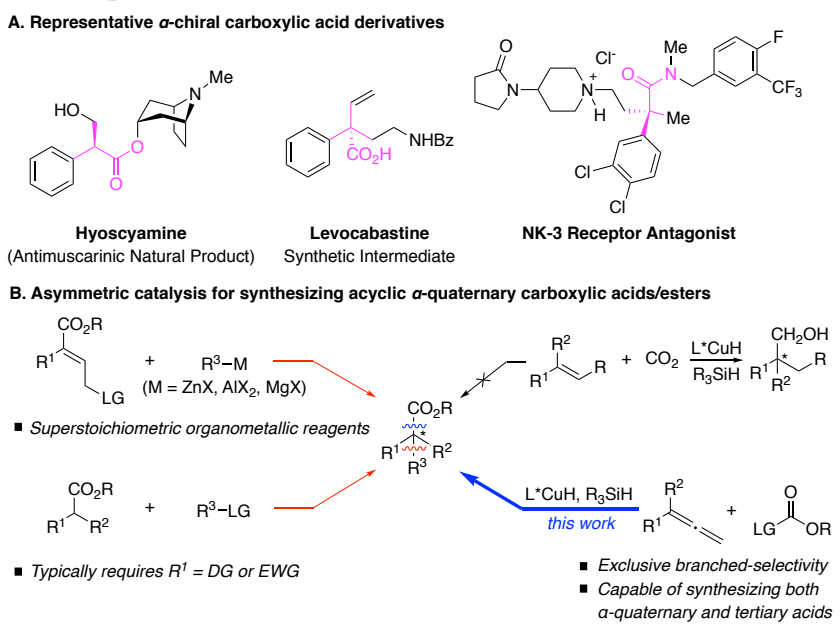

Figure 1. A. Overview of bioactive $\alpha$-chiral carboxylic acid derivatives. B. Previous strategies and our approach to synthesize acyclic $\alpha$-quaternary carboxylic acid derivatives. 
We chose 1-phenyl-1-methylallene (1a) as our model substrate since the branched selective hydrocarboxylation of 1aryl-1-alkylallenes would produce valuable acyclic quaternary $\alpha$-vinyl- $\alpha$-aryl carboxylic acids that have been used as intermediates in the preparation of $(+)$-epilaurene ${ }^{3 \mathrm{~d}}$ and several pharmaceutical ingredients. $^{3 \mathrm{~b}, 14 \mathrm{a}}$ We began our investigation with diphenyl carbonate (2a) as the reagent for carboxylate introduction. A series of chiral bisphosphine ligands were evaluated in the hydrocarboxylation of 1a with diphenyl carbonate (Table S1), and the highest level of enantioselectivity was obtained with $(R, R)$-Ph-BPE (L1). Under these conditions, the ester product was formed in $42 \%$ yield (90:10 er) exclusively as the branched isomer (Table 1, entry 1). In addition to the moderate level of enantioselectivity that was observed, the use of $\mathbf{2 a}$ appeared to result in a sluggish reaction rate. We next attempted to improve the activity of electrophile by replacing 2a with $\mathrm{Boc}_{2} \mathrm{O}$ (2b) or methyl chloroformate (2c), which resulted in no desired hydroesterification product being formed (Table 1, entries 2-3). With 2c, we needed an alkoxide base to regenerate $\mathrm{LCuH}$ from a $\mathrm{LCuCl}$ intermediate, ${ }^{22}$ and we ascribed the low yield to the incompatibility between the base and methyl chloroformate. Since $\mathrm{LCuH}$ regeneration from $\mathrm{LCuF}$ complexes can proceed in the absence of a base additives, ${ }^{23}$ we investigated the use of fluoroformates as potential carboxylation reagents. When commercially available 1adamantyl fluoroformate (2d) was employed, product $\mathbf{3}$ was obtained in $83 \%$ yield (Table 1 , entry 4 ). Upon reexamining the suitability of different ligands in reactions with $2 \mathbf{d}$ (Table 1 , entry 5-6, and Table S2), we found that when (R)-DTBMSEGPHOS (L2) was used (Table 1, entry 5), the branched product was obtained as a single regioisomer in $92 \%$ yield and 99:1 er.

Table 1. Evaluation of Reaction Conditions for the $\mathrm{CuH}-$ Catalyzed Hydrocarboxylation of Allene ${ }^{a}$

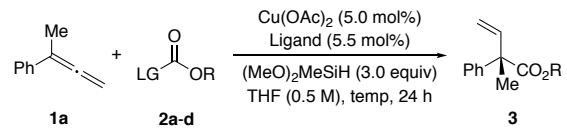

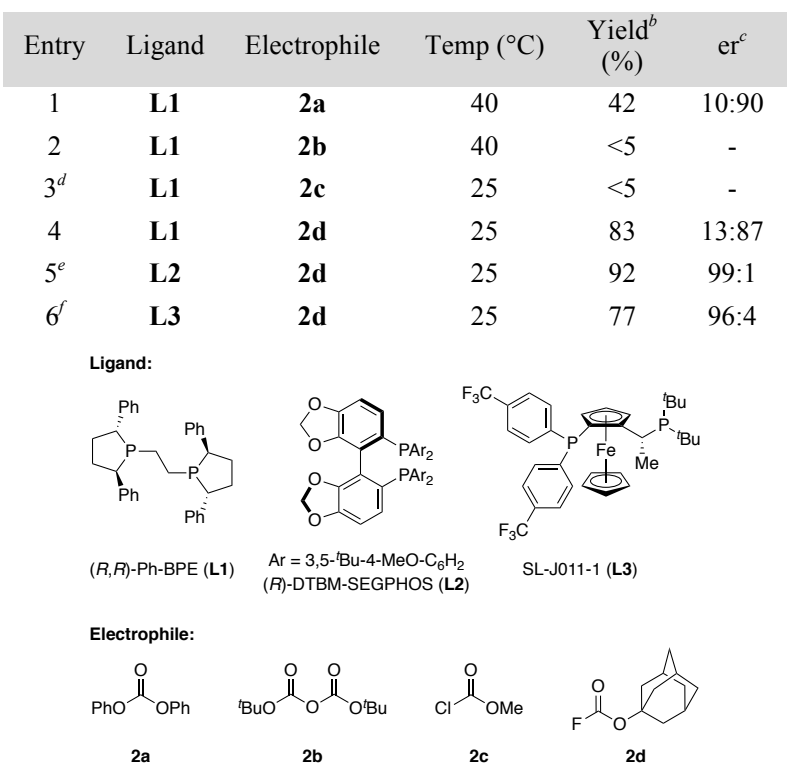

${ }^{a}$ Conditions: $0.10 \mathrm{mmol} 2$ (1.0 equiv), 1a (2.0 equiv), copper (II) acetate $(5.0 \mathrm{~mol} \%)$, ligand $(5.5 \mathrm{~mol} \%)$, dimethoxy(methyl)silane (3.0 equiv) in THF $(0.5 \mathrm{M}) .{ }^{b}$ Yield was determined by ${ }^{1} \mathrm{H}$ NMR spectroscopy of the crude reaction mix- ture, using 1,3,5-trimethoxybenzene as an internal standard. ${ }^{c}$ Enantiomeric ratio was determined by SFC analysis. ${ }^{d}$ Either Li$\mathrm{OMe}$ (1.1 equiv) or $\mathrm{CsOBz}$ (1.1 equiv) was used as an additive; $\mathbf{1 a}$ (1.5 equiv) was used. ${ }^{e} \mathbf{1 a}$ (1.2 equiv) was used. ${ }^{f} \mathbf{1}$ ( 1.0 equiv) and 2 ( 1.2 equiv) were used.

Table 2. Substrate Scope for the CuH-Catalyzed Hydrocarboxylation of Allenes ${ }^{a}$

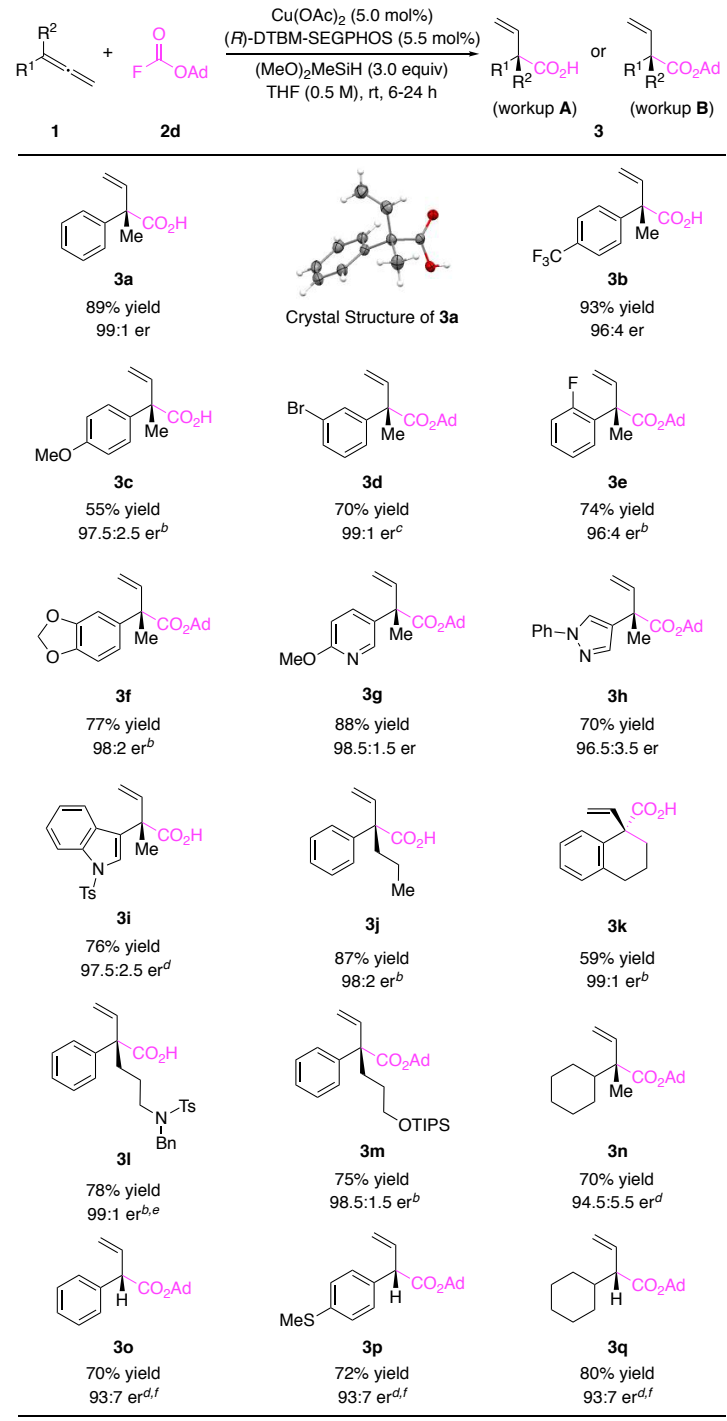

${ }^{a}$ Conditions: $0.50 \mathrm{mmol}$ 2d (1.0 equiv), 1 (1.2 equiv), copper (II) acetate (5.0 mol\%), L2 (5.5 mol\%), dimethoxy(methyl)silane (3.0 equiv) in THF $(0.5 \mathrm{M})$; workup $\mathbf{A}$ : $\mathrm{NH}_{4} \mathrm{~F} / \mathrm{MeOH}$ workup followed by hydrolysis using TFA; workup B: $\mathrm{NH}_{4} \mathrm{~F} / \mathrm{MeOH}$ workup; yields refer to average isolated yields of two runs; see the Supporting Information for details. ${ }^{b}$ Reaction was carried out at $40{ }^{\circ} \mathrm{C}$. ${ }^{c}$ Reaction was carried out at $30{ }^{\circ} \mathrm{C}$. ${ }^{d} \mathbf{L 3}$ was used as the ligand instead. ${ }^{e} \mathbf{1}$ (1.1 equiv) was used. ${ }^{f}$ Reaction was carried out at $0{ }^{\circ} \mathrm{C}$ in 1,2-dimethoxyethane (DME, $1.0 \mathrm{~mL}$ ).

With the optimal reaction conditions identified, we first examined the substrate scope using 1,1-disubstituted allenes (Table 2). We found that a broad range of 1,1-disubstituted allenes in combination with $\mathbf{2 d}$ were transformed to the desired products in good yields and with excellent enantioselectivity. Moreover, the ester products could be easily hydrolyzed to carboxylic acids in the presence of trifluoroacetic acid (TFA) in near quantitative yields. To demonstrate the feasibil- 
ity of this in situ hydrolysis protocol, half of the ester products in Table 2 were isolated as carboxylic acids $(\mathbf{3 a}-\mathbf{c}, \mathbf{3 i}-\mathbf{l})$ without any purification of the intermediate esters. ${ }^{24} 1$-Aryl-1alkylallenes bearing an electron-withdrawing (3b) and donating group (3c) on the arenes were both compatible. Additionally, reactions of arenes substituted with para- $(\mathbf{3 b}, \mathbf{3} \mathbf{c})$, meta- (3d), and ortho- (3e) groups resulted in the formation of the products in high yields and enantioselectivity. Functional groups such as an acetal (3f), a sulfonamide (3I), and a siloxy group (3m) were also well tolerated. Allenes containing heterocycles, including a pyridine $\mathbf{( 3 g}$ ) and pyrazole (3h), were suitable substrates for the hydrocarboxylation reaction. However, when an allene substituted with an indole (3i) was utilized, better results were found if ligand $\mathbf{L 3}$ was used in place of $\mathbf{L 2}$. We speculate that this is due to the sterically demanding environment of the substrate that requires the use of a less bulky ligand. Allenes containing functionalized primary alkyl groups $(\mathbf{3} \mathbf{j}, \mathbf{3} \mathbf{3}-\mathbf{m})$ as well as an exocyclic allene $(\mathbf{3 k})$ were also accommodated in this protocol. Furthermore, 1-cyclohexyl-1methylallene (3n) was efficiently transformed to the hydroxycarboxylation product when ligand $\mathbf{L 3}$ was employed.

We were also interested in expanding this method toward the synthesis of $\alpha$-tertiary esters, which under many conditions are difficult to access in high enantioselectivity due to the easily epimerizable stereogenic center. Thus, we next examined the reaction of a monosubstituted allene, phenylallene (10), under our standard reaction conditions. However, the product ester was formed with a poor level of enantioselectivity, 69.5:30.5 er (Table S4). After reevaluating the reaction parameters, the carboxylation product 3o could be isolated in $70 \%$ yield and 93:7 er using $\mathbf{L 3}$ as ligand (Table 2). A thioether-containing 1-aryl allene (1p) and cyclohexylallene (1q) were also converted to the corresponding $\alpha$-tertiary esters in good yields and high enantioselectivity.

To further demonstrate the synthetic utility of our method, we examined the transformation of the hydrocarboxylation products into compounds of interest (Scheme 1). For example, chiral $\alpha$-tertiary amines are found in a variety of natural products and biologically active compounds, and are difficult to access in an enantioenriched form by standard hydroamination reactions. ${ }^{25}$ By employing a Curtius Rearrangement, we were able to convert $\alpha$-quaternary carboxylic acid 3a to $\alpha$-tertiary amine $\mathbf{6}$ in a stereoretentive fashion (Scheme 1a). Additionally, we sought to apply our hydrocarboxylation products to the synthesis of enantioenriched $\gamma$-amino acid derivatives, which play an important role as $\gamma$-aminobutyric acid transaminase inhibitors and in peptide chemistry. ${ }^{26}$ Derivatization of the resulting vinyl group in $\mathbf{3 d}$, an $\alpha$-quaternary $\gamma$-amino ester $\mathbf{8}$ could be accomplished using a $\mathrm{CuH}$-catalyzed hydroamination reaction $^{27}$ (Scheme 1b). We also utilized the method for the preparation of the pharmaceutical indobufen, a platelet aggregation inhibitor marketed under brand name Ibustrin. ${ }^{28}(S)$ Indobufen, previously prepared by the separation of the racemic mixture, ${ }^{29 c}$ was found to be far more potent than the $(R)$-enantiomer in terms of its antiplatelet and antiinflammatory activities, ${ }^{29}$ and thus an enantioselective synthetic route to $(S)$-indobufen would be of interest. In our approach, $\mathrm{CuH}$-catalyzed hydrocarboxylation of allene $\mathbf{1 r}$ gave ester 3r, which underwent subsequent hydrogenation and hydrolysis to furnish $(S)$-Indobufen (10) in $76 \%$ overall yield and 92:8 er, without the need for any chromatographic purification.
Scheme 1. Applications of the CuH-catalyzed Hydrocarboxylation Reactions ${ }^{a}$
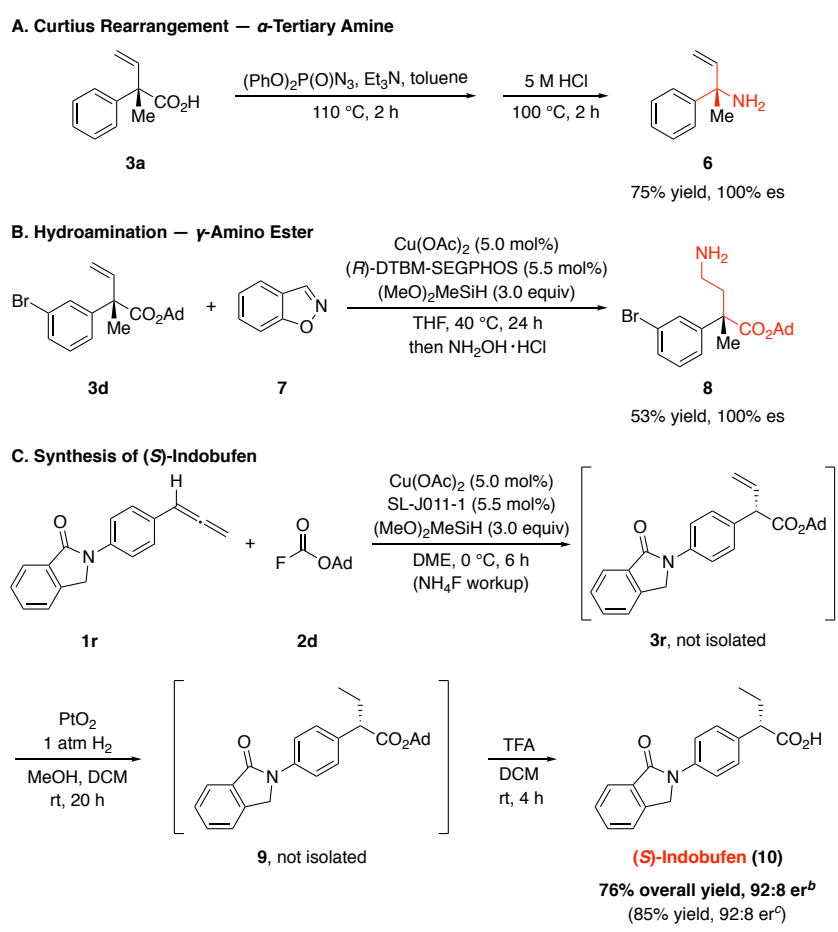

${ }^{a}$ See the Supporting Information for experimental details. ${ }^{b} \mathbf{1 r}$ (1.0 equiv) and $\mathbf{2 d}$ ( 1.2 equiv) were used. ${ }^{c} \mathbf{2 d}$ ( 1.0 equiv) and 1r (1.2 equiv) were used.

Based on previous DFT calculations on $\mathrm{CuH}$-catalyzed reactions involving allenes, ${ }^{30}$ a plausible mechanism can be proposed for this transformation, as depicted in Figure 2. An allene (1) first undergoes hydrocupration with a $\mathrm{CuH}$ catalyst to generate a rapidly equilibrating mixture of allylcopper species (B and $\mathbf{C})$. The less hindered terminal allylic copper (B) reacts preferentially with fluoroformate $\mathbf{2 d}$ through an enantiodetermining six-membered transition state $(\mathbf{D})$, to form intermediate E. Subsequent collapse of the tetrahedral intermediate by $\beta$-fluoride elimination leads to the branched carboxylation product 3 and $\mathrm{CuF}$. A $\sigma$-bond metathesis reaction between $\mathrm{CuF}$ and the silane regenerates the $\mathrm{CuH}$ catalyst.

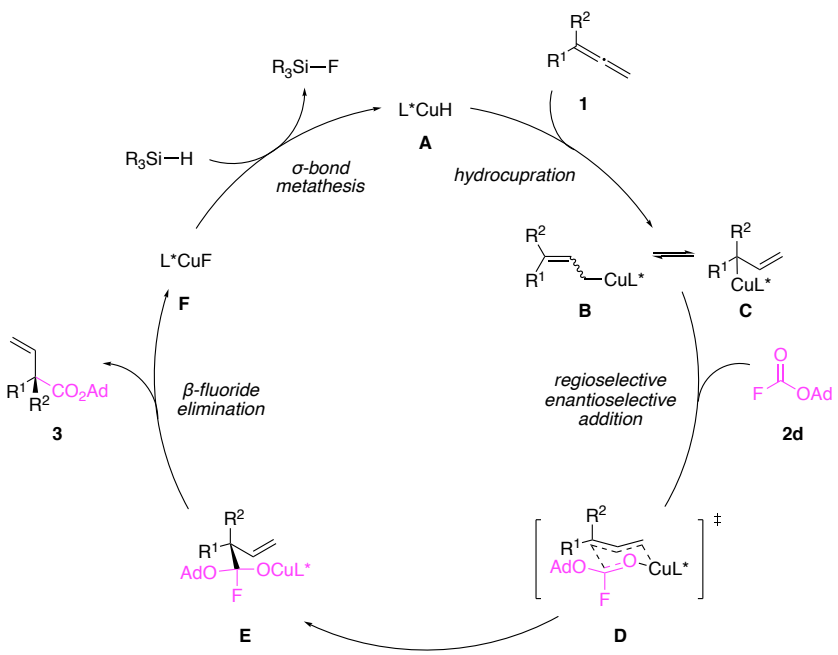

Figure 2. Proposed mechanism for the CuH-catalyzed hydrocarboxylation of allenes 
In conclusion, we have developed a highly enantioselective $\mathrm{CuH}$-catalyzed hydrocarboxylation to synthesize $\alpha$-chiral carboxylic acids and esters, in particular $\alpha$-quaternary ones. A commercially available fluoroformate was used as the carboxylation reagent to react with allenes in exclusive branched selectivity. The reaction proceeded under mild conditions and could tolerate a variety of important functional groups and heterocycles. Further derivatization of the carboxylation products provided other pharmaceutically and synthetically useful scaffolds. We anticipate that this carboxylation strategy using a fluoroformate may be extended to the discovery of other types of important asymmetric carboxylation processes.

\section{ASSOCIATED CONTENT}

\section{Supporting Information}

The Supporting Information is available free of charge on the ACS Publications website.

Experimental procedures and spectral data (PDF)

X-ray crystallographic data for 3a (CIF)

\section{AUTHOR INFORMATION}

\section{Corresponding Author}

Stephen L. Buchwald - Department of Chemistry, Massachusetts Institute of Technology, Cambridge, Massachusetts 02139, United States; orcid.org/0000-0003-3875-4775; Email: sbuchwal@mit.edu

\section{Author}

Sheng Feng - Department of Chemistry, Massachusetts Institute of Technology, Cambridge, Massachusetts 02139, United States; orcid.org/0000-0001-8781-9681

\section{Notes}

The authors declare no competing financial interest.

\section{ACKNOWLEDGMENT}

Research reported in this publication was supported by the $\mathrm{Na}-$ tional Institutes of Health under award number R35-GM122483. The content is solely the responsibility of the authors and does not necessarily represent the official views of the National Institutes of Health. Solvias AG is acknowledged for a generous gift of SLJ011-1. We thank Drs. Veronika Kottisch, Alexander Schuppe, and Christine Nguyen for their advice on the preparation of this manuscript. We acknowledge Dr. Peter Müller (MIT) for X-ray crystallographic analysis of 3a. We thank the National Institutes of Health for a supplemental grant for the purchase of supercritical fluid chromatography (SFC) equipment (GM058160-17S1).

\section{REFERENCES}

(1) (a) Hu, P.; Chi, H. M.; DeBacker, K. C.; Gong, X.; Keim, J. H.; Hsu, I. T.; Snyder, S. A. Quaternary-Centre-Guided Synthesis of Complex Polycyclic Terpenes. Nature 2019, 569, 703-707. (b) Ling, T.; Rivas, F. All-Carbon Quaternary Centers in Natural Products and Medicinal Chemistry: Recent Advances. Tetrahedron 2016, 72, 6729-6777. (c) Li, C.; Ragab, S. S.; Liu, G.; Tang, W. Enantioselective Formation of Quaternary Carbon Stereocenters in Natural Product Synthesis: A Recent Update. Nat. Prod. Rep. 2020, 37, 276-292. (d) Christoffers, J.; Baro, A. Quaternary Stereocenters: Challenges and Solutions for Organic Synthesis; Wiley-VCH, 2005.
(2) (a) Feng, J.; Holmes, M.; Krische, M. J. Acyclic Quaternary Carbon Stereocenters via Enantioselective Transition Metal Catalysis. Chem. Rev. 2017, 117, 12564-12580. (b) Das, J. P.; Marek, I. Enantioselective Synthesis of All-Carbon Quaternary Stereogenic Centers in Acyclic Systems. Chem. Commun. 2011, 47, 4593-4623. (c) Quasdorf, K.; Overman, L. E. Catalytic Enantioselective Synthesis of Quaternary Carbon Stereocentres. Nature 2014, 516, 181-191. (d) Zeng, X.; Cao, Z.; Wang, Y.; Zhou, F.; Zhou, J. Catalytic Enantioselective Desymmetrization Reactions to All-Carbon Quaternary Stereocenters. Chem. Rev. 2016, 116, 7330-7396.

(3) (a) Hoyle, J. The Synthetic Uses of Carboxylic Acids and Their Derivatives. In The Chemistry of Acid Derivatives; Wiley, 1992. Vol 2. (b) Shockley, S. E.; Hethcox, J. C.; Stoltz, B. M. Compositions and Methods for Preparing $\beta, \gamma$-Unsaturated Acids. International Patent WO 209243 (A1), Nov. 15, 2018. (c) Hanessian, S.; Jennequin, T.; Boyer, N.; Babonneau, V.; Soma, U.; Mannoury la Cour, C.; Millan, M. J.; De Nanteuil, G. Design, Synthesis, and Optimization of Balanced Dual $\mathrm{NK}_{1} / \mathrm{NK}_{3}$ Receptor Antagonists. ACS Med. Chem. Lett. 2014, 5, 550-555. (d) Knust, H.; Nettekoven, M.; Ratni, H.; Vifian, W.; Wu, X. Piperidine Derivatives as NK3 Receptor Antagonists. International Patent WO 033995 (A1), Mar. 19, 2009. (d) Fadel, A.; Canet, J.-L.; Salaün, J. Asymmetric Construction of Quaternary Carbons from Chiral Malonates: Total Syntheses of $(+)$-Epilaurene and (-)-Isolaurene. Tetrahedron: Asymmetry 1993, 4, 27-30.

(4) (a) Bioactive Carboxylic Compound Classes: Pharmaceuticals and Agrochemicals. Lamberth, C.; Dinges, J., Eds.; Wiley-VCH, 2016. (b) Ramadan, M.; Goeters, S.; Watzer, B.; Krause, E.; Lohmann, K.; Bauer, R.; Hempel, B.; Imming, P. Chamazulene Carboxylic Acid and Matricin: A Natural Profen and Its Natural Prodrug, Identified through Similarity to Synthetic Drug Substances. J. Nat. Prod. 2006, 69, 1041-1045. (c) Gülcan, H. O.; Ünlü, S.; Dimoglo, A.; Şahin, Y.; Esiringu, I.; Erçetin, T.; Öz, D.; Şahin, M. F. Marginally Designed New Profen Analogues Have the Potential to Inhibit $\mathrm{Cy}-$ clooxygenase Enzymes. Arch. Pharm. Chem. Life Sci. 2015, 348, $55-61$.

(5) Corey, E. J.; Kürti, L. Enantioselective Chemical Synthesis: Methods, Logic and Practice; Direct Book Publishing, 2010.

(6) Zhu, S.; Zhou, Q. Iridium-Catalyzed Asymmetric Hydrogenation of Unsaturated Carboxylic Acids. Acc. Chem. Res. 2017, 50, 988-1001.

(7) For selected reviews and reports, see: (a) Zhang, X. P.; Cui, X. Asymmetric $\mathrm{C}-\mathrm{H}$ Functionalization by Transition Metal-Catalyzed Carbene Transfer Reactions. In Comprehensive Organic Synthesis, 2nd ed.; Elsevier, 2014; Vol 7, pp 86-120. (b) Davies, H. M. L.; Liao, K. Dirhodium Tetracarboxylates as Catalysts for Selective Intermolecular C-H Functionalization. Nat. Rev. Chem. 2019, 3, 347-360. (c) Qiu, H.; Li, M.; Jiang, L.; Lv, F.; Zan, L.; Zhai, C..; Doyle, M. P.; Hu, W. Highly Enantioselective Trapping of Zwitterionic Intermediates by Imines. Nat. Chem. 2012, 4, 733-738.

(8) (a) Mohr, J. T.; Hong, A. Y.; Stoltz, B. M. Enantioselective Protonation. Nat. Chem. 2009, 1, 359-369. (b) Chen, X.; Fong, J. Z. M.; Xu, J.; Mou, C.; Lu, Y.; Yang, S.; Song, B.; Chi, Y. R. CarbeneCatalyzed Dynamic Kinetic Resolution of Carboxylic Esters. J. Am. Chem. Soc. 2016, 138, 7212-7215.

(9) Sandoval, B. A.; Meichan, A. J.; Hyster, T. K. Enantioselective Hydrogen Atom Transfer: Discovery of Catalytic Promiscuity in Flavin-Dependent 'Ene'-Reductases. J. Am. Chem. Soc. 2017, 139, 11313-11316.

(10) For selected reviews and examples on enantioselective $\alpha$ functionalization of carboxylic acids/esters/silyl ketene acetals for the synthesis of $\alpha$-tertiary/cyclic $\alpha$-quaternary carboxylic acids or esters, see: (a) Cheng, Q.; Tu, H.; Zheng, C.; Qu, J.; Helmchen, G.; You, S. Iridium-Catalyzed Asymmetric Allylic Substitution Reactions. Chem. Rev. 2019, 119, 1855-1969. (b) Schwarz, K. J.; Amos, J. L.; Klein, C.; Do, D. T.; Snaddon, T. N. Uniting C1-Ammonium Enolates and Transition Metal Electrophiles via Cooperative Catalysis: The Direct Asymmetric $\alpha$-Allylation of Aryl Acetic Acid Esters. J. Am. Chem. Soc. 2016, 138, 5214-5217. (c) Jiang, X.; Beiger, J. J.; Hartwig, J. F. Stereodivergent Allylic Substitutions with Aryl Acetic Acid Esters by Synergistic Iridium and Lewis Base Catalysis. J. Am. Chem. Soc. 2017, 139, 87-90. (d) Kotani, S.; Yoshiwara, Y.; Ogasawara, M.; 
Sugiura, M.; Nakajima, M. Catalytic Enantioselective Aldol Reactions of Unprotected Carboxylic Acids under Phosphine Oxide Catalysis. Angew. Chem., Int. Ed. 2018, 57, 15877-15881. (e) Schwarz, K. J.; Yang, C.; Fyfe, J. W. B.; Snaddon, T. N. Enantioselective $\alpha$ Benzylation of Acyclic Esters Using $\pi$-Extended Electrophiles. Angew. Chem., Int. Ed. 2018, 57, 12102-12105. (f) Spielvogel, D. J.; Buchwald, S. L. Nickel-BINAP Catalyzed Enantioselective $\alpha$ Arylation of $\alpha$-Substituted $\gamma$-Butyrolactones. J. Am. Chem. Soc. 2002, 124, 3500-3501. (g) Mermerian, A. H.; Fu, G. C. Catalytic Enantioselective Construction of All-Carbon Quaternary Stereocenters: Synthetic and Mechanistic Studies of the C-Acylation of Silyl Ketene Acetals. J. Am. Chem. Soc. 2005, 127, 5604-5607. (h) Huang, Z.; Liu, Z.; Zhou, J. An Enantioselective, Intermolecular $\alpha$-Arylation of Ester Enolates To Form Tertiary Stereocenters. J. Am. Chem. Soc. 2011, 133, 15882-15885. (i) Jette, C. I.; Tong, Z, J.; Hadt, R. G.; Stoltz, B. M. Copper-Catalyzed Enantioselective Allylic Alkylation with a $\gamma$-Butyrolactone-Derived Silyl Ketene Acetal. Angew. Chem., Int. Ed. 2020, 59, 2033-2038. (j) Kim, B.; Kim, Y.; Lee, S. Y. Stereodivergent Carbon-Carbon Bond Formation between Iminium and Enolate Intermediates by Synergistic Organocatalysis. J. Am. Chem. Soc. 2021, 143, 73-79.

(11) For reports on enantioselective $\alpha$-functionalization of carboxylic acids/esters for the synthesis of acyclic $\alpha$-quaternary carboxylic acids/esters, see: (a) Fujita, T.; Yamamoto, T.; Morita, Y.; Chen, H.; Shimizu, Y.; Kanai, M. Chemo- and Enantioselective Pd/B Hybrid Catalysis for the Construction of Acyclic Quaternary Carbons: Migratory Allylation of $O$-Allyl Esters to $\alpha$-C-Allyl Carboxylic Acids. $J$. Am. Chem. Soc. 2018, 140, 5899-5903. (b) He, Z.; Jiang, X.; Hartwig, J. F. Stereodivergent Construction of Tertiary Fluorides in Vicinal Stereogenic Pairs by Allylic Substitution with Iridium and Copper Catalysts. J. Am. Chem. Soc. 2019, 141, 13066-13073. (c) Zhu, Y.; Zhang, L.; Luo, S. Asymmetric $\alpha$-Photoalkylation of $\beta$-Ketocarbonyls by Primary Amine Catalysis: Facile Access to Acyclic All-Carbon Quaternary Stereocenters. J. Am. Chem. Soc. 2014, 136, 14642-14645. (d) Wang, D.; Zhang, L.; Luo, S. Enantioselective Decarboxylative $\alpha$-Alkynylation of $\beta$-Ketocarbonyls via a Catalytic $\alpha$ Imino Radical Intermediate. Org. Lett. 2017, 19, 4924-4927. (e) Wang, Y.; Chai, J.; You, C.; Zhang, J.; Mi, X.; Zhang, L.; Luo, S. $\pi$ Coordinating Chiral Primary Amine/Palladium Synergistic Catalysis for Asymmetric Allylic Alkylation. J. Am. Chem. Soc. 2020, 142, 3184-3195. (f) Xie, X.; Chen, Y.; Ma, D. Enantioselective Arylation of 2-Methylacetoacetates Catalyzed by CuI/trans-4-Hydroxy-LProline at Low Reaction Temperatures. J. Am. Chem. Soc. 2006, 128 , 16050-16051. (g) Liu, W.-B.; Reeves, C. M.; Stoltz, B. M. Enantio-, Diastereo-, and Regioselective Iridium-Catalyzed Asymmetric Allylic Alkylation of Acyclic $\beta$-Ketoesters. J. Am. Chem. Soc. 2013, 135, 17298-17301. (h) Sawamura, M.; Sudoh, M.; Ito, Y. An Enantioselective Two-Component Catalyst System: Rh-Pd-Catalyzed Allylic Alkylation of Activated Nitriles. J. Am. Chem. Soc. 1996, 118, 3309-3310. (i) Asad, S. A.; Ulicki, J.; Shevyrev, M.; Uddin, N.; Alberch, E.; Hossain, M. M. First Example of the Intermolecular Palladium-Catalyzed Asymmetric Allylic Alkylation of Hydroxyacrylates: Synthesis of All-Carbon $\alpha$-Aryl Quaternary Aldehydes. Eur. J. Org. Chem. 2014, 5695-5699. (j) Hashimoto, T.; Sakata, K.; Maruoka, K. $\alpha$-Chiral Acetylenes Having an All-Carbon Quaternary Center: Phase Transfer Catalyzed Enantioselective $\alpha$-Alkylation of $\alpha$-Alkyl- $\alpha$ alkynyl Esters. Angew. Chem., Int. Ed. 2009, 48, 5014-5017.

(12) For selected examples on enantioconvergent cross-coupling of racemic $\alpha$-halo esters, see: (a) Dai, X.; Strotman, N. A.; Fu, G. C. Catalytic Asymmetric Hiyama Cross-Couplings of Racemic $\alpha$-Bromo Esters. J. Am. Chem. Soc. 2008, 130, 3302-3303. (b) Mao, J.; Liu, F.; Wang, M.; Wu, L.; Zheng, B.; Liu, S.; Zhong, J.; Bian, Q.; Walsh, P. J. Cobalt-Bisoxazoline-Catalyzed Asymmetric Kumada CrossCoupling of Racemic $\alpha$-Bromo Esters with Aryl Grignard Reagents. J. Am. Chem. Soc. 2014, 136, 17662-17668. (c) Jin, M.; Adak, L.; Nakamura, M. Iron-Catalyzed Enantioselective Cross-Coupling Reactions of $\alpha$-Chloroesters with Aryl Grignard Reagents. J. Am. Chem. Soc. 2015, 137, 7128-7134. (d) Guan, H.; Zhang, Q.; Walsh, P. J.; Mao, J. Nickel/Photoredox-Catalyzed Asymmetric Reductive CrossCoupling of Racemic $\alpha$-Chloro Esters with Aryl Iodides. Angew. Chem., Int. Ed. 2020, 59, 5172-5177. (e) Wang, Z.; Yin, H.; Fu, G. C.
Catalytic Enantioconvergent Coupling of Secondary and Tertiary Electrophiles with Olefins. Nature 2018, 563, 379-383. (f) Wang, Z.; Yang, Z.; Fu, G. C. Quaternary Stereocentres via Catalytic Enanti oconvergent Nucleophilic Substitution Reactions of Tertiary Alkyl Halides. Nat. Chem. 2021, https://doi.org/10.1038/s41557-020-006097.

(13) A chiral auxiliary-based approach showed two examples for accessing acids with an all-carbon $\alpha$-quaternary center: Yu, K.; Lu, P.; Jackson, J. J.; Nguyen, T. D.; Alvarado, J.; Stivala, C. E.; Ma, Y.; Mack, K. A.; Hayton, T. W.; Collum, D. B.; Zakarian, A. Lithium Enolates in the Enantioselective Construction of Tetrasubstituted Carbon Centers with Chiral Lithium Amides as Noncovalent Stereodirecting Auxiliaries. J. Am. Chem. Soc. 2017, 139, 527-533.

(14) (a) Murphy, K. E.; Hoveyda, A. H. Catalytic Enantioselective Synthesis of Quaternary All-Carbon Stereogenic Centers. Preparation of $\alpha, \alpha^{\prime}$-Disubstituted $\beta, \gamma$-Unsaturated Esters through $\mathrm{Cu}$-Catalyzed Asymmetric Allylic Alkylations. Org. Lett. 2005, 7, 1255-1258. (b) Lee, Y.; Hoveyda, A. H. Lewis Base Activation of Grignard Reagents with $\mathrm{N}$-Heterocyclic Carbenes. Cu-Free Catalytic Enantioselective Additions to $\gamma$-Chloro- $\alpha, \beta$-Unsaturated Esters. J. Am. Chem. Soc. 2006, 128, 15604-15605. (c) Gao, F.; Lee, Y.; Mandai, K.; Hoveyda, A. H. Quaternary Carbon Stereogenic Centers through CopperCatalyzed Enantioselective Allylic Substitutions with Readily Accessible Aryl- or Heteroaryllitium Reagents and Aluminum Chlorides. Angew. Chem., Int. Ed. 2010, 49, 8370-8374. (d) Shockley, S. E.; Hethcox, J. C.; Stoltz, B. M. Enantioselective Synthesis of Acyclic $\alpha-$ Quaternary Carboxylic Acid Derivatives through Iridium-Catalyzed Allylic Alkylation. Angew. Chem., Int. Ed. 2017, 56, 11545-11548.

(15) For selected recent examples on racemic hydrocarboxylation using $\mathrm{CO}_{2}$, see: (a) Takaya, J.; Iwasawa, N. Hydrocarboxylation of Allenes with $\mathrm{CO}_{2}$ Catalyzed by Silyl Pincer-Type Palladium Complex. J. Am. Chem. Soc. 2008, 130, 15254-15255. (b) Williams, C. M.; Johnson, J. B.; Rovis, T. Nickel-Catalyzed Reductive Carboxylation of Styrenes Using $\mathrm{CO}_{2}$. J. Am. Chem. Soc. 2008, 130, 14936-14937. (c) Gaydou, M.; Moragas, T.; Juliá-Hernández, F.; Martin, R. Site-Selective Catalytic Carboxylation of Unsaturated Hydrocarbons with $\mathrm{CO}_{2}$ and Water. J. Am. Chem. Soc. 2017, 139, 12161-12164. (d) Seo, H.; Liu, A.; Jamison, T. F. Direct $\beta$-Selective Hydrocarboxylation of Styrenes with $\mathrm{CO}_{2}$ Enabled by Continuous Flow Photoredox Catalysis. J. Am. Chem. Soc. 2017, 139, 13969-13972. (e) Meng, Q.; Wang, S.; Huff, G. S.; König, B. Ligand-Controlled Regioselective Hydrocarboxylation of Styrenes with $\mathrm{CO}_{2}$ by Combining Visible Light and Nickel Catalysis. J. Am. Chem. Soc. 2018, 140, 3198-3201. (f) Alkayal, A.; Tabas, V.; Montanaro, S.; Wright, I. A.; Malkov, A. V.; Buckley, B. R. Harnessing Applied Potential: Selective $\beta$-Hydrocarboxylation of Substituted Olefins. $J$. Am. Chem. Soc. 2020, 142, 1780-1785. (g) Fujihara, T.; Xu, T.; Semba, K.; Terao, J.; Tsuji, Y. Copper-Catalyzed Hydrocarboxylation of Alkynes Using Carbon Dioxide and Hydrosilanes. Angew. Chem., Int. Ed. 2011, 50, 523-527. (h) Tani, Y.; Kuga, K.; Fujihara, T.; Terao, J.; Tsuji, Y. Copper-Catalyzed C-C Bond-Forming Transformation of $\mathrm{CO}_{2}$ to Alcohol Oxidation Level: Selective Synthesis of Homoallylic Alcohols from Allenes, $\mathrm{CO}_{2}$, and Hydrosilanes. Chem. Commun. 2015, 51, 13020-13023.

(16) For selected recent examples on racemic hydroxy- and alkoxycarbonylation using CO, see: (a) Li, H.; Dong, K.; Jiao, H.; Neumann, H.; Jackstell, R.; Beller, M. The Scope and Mechanism of Palladium-Catalysed Markovnikov Alkoxycarbonylation of Alkenes. Nat. Chem. 2016, 8, 1159-1166. (b) Dong, K.; Fang, X.; Gülak, S.; Franke, R.; Spannenberg, A.; Neumann, H.; Jackstell, R.; Beller, M. Highly Active and Efficient Catalysts for Alkoxycarbonylation of Alkenes. Nat. Commun. 2017, 8, 1-7. (c) Yang, J.; Liu, J.; Neumann, H.; Franke, R.; Jackstell, R.; Beller, M. Direct Synthesis of Adipic Acid Esters via Palladium-Catalyzed Carbonylation of 1,3-Dienes. Science 2019, 366, 1514-1517. (d) Sang, R.; Kucmierczyk, P.; Dühren, R.; Razzaq, R.; Dong, K.; Liu, J.; Franke, R.; Jackstell, R.; Beller, M. Synthesis of Carboxylic Acids by Palladium-Catalyzed Hydroxycarbonylation. Angew. Chem., Int. Ed. 2019, 58, 14365-14373.

(17) A hydrocarboxylation example for accessing $\alpha$-quaternary centers with up to $66 \%$ ee: (a) Kawashima, S.; Aikawa, K.; Mikami, 
K. Rhodium-Catalyzed Hydrocarboxylation of Olefins with Carbon Dioxide. Eur. J. Org. Chem. 2016, 3166-3170. An asymmetric copper-catalyzed hydroamidation of vinyl arenes using $\mathrm{CO}$ gas was reported recently: (b) Yuan, Y.; Wu, F.; Schünemann, C.; Holz, J.; Kamer, P. C. J.; Wu, X. Copper-Catalyzed Carbonylative Hydroamidation of Styrenes to Branched Amides. Angew. Chem., Int. Ed. 2020, 59, 22441-22445.

(18) For a review, see: Godard, C.; Muñoz, B. K.; Ruiz, A.; Claver, C. Pd-Catalysed Asymmetric Mono- and Bis-Alkoxycarbonylation of Vinylarenes. Dalton Trans. 2008, 853.

(19) For selected examples on asymmetric hydrocarboxylation of alkenes using CO or its surrogate, see: (a) Cometti, G.; Chiusoli, G. P. Asymmetric Induction in Carbomethoxylation of Vinylaromatics. $J$. Organomet. Chem. 1982, 236, C31-C32. (b) Alper, H.; Hamel, N. Asymmetric Synthesis of Acids by the Palladium-Catalyzed Hydrocarboxylation of Olefins in the Presence of $(R)-(-)-$ or $(S)-(+)-1,1^{\prime}$ Binaphthyl-2,2'-diyl Hydrogen Phosphate. J. Am. Chem. Soc. 1990, 112, 2803-2804. (c) Cao, P.; Zhang, X. Highly Enantioselective Cyclocarbonylation of Allylic Alcohols Catalyzed by Novel Pd-1,4bisphosphine Complexes. J. Am. Chem. Soc. 1999, 121, 7708-7709. (d) Konrad, T. M.; Fuentes, J. A.; Slawin, A. M. Z.; Clarke, M. L. Highly Enantioselective Hydroxycarbonylation and Alkoxycarbonylation of Alkenes using Dipalladium Complexes as Precatalysts. Angew. Chem., Int. Ed. 2010, 49, 9197-9200. (e) Li, J.; Chang, W.; Ren, W.; Dai, J.; Shi, Y. Palladium-Catalyzed Highly Regio- and Enantioselective Hydroesterification of Aryl Olefins with Phenyl Formate. Org. Lett. 2016, 18, 5456-5459. (f) Li, J.; Ren, W.; Dai, J. Shi, Y. Palladium-Catalyzed Regio- and Enantioselective Hydroesterification of Aryl Olefins with CO Gas. Org. Chem. Front. 2018, 5, 75-79. (g) Tian, D.; Xu, R.; Zhu, J.; Huang, J.; Dong, W.; Claverie, J.; Tang, W. Asymmetric Hydroesterification of Diarylmethyl Carbinols. Angew. Chem., Int. Ed. 2021, https://doi.org/10.1002/anie.202015450.

(20) For reviews and selected examples, see: (a) Pirnot, M. T.; Wang, Y.; Buchwald, S. L. Copper Hydride Catalyzed Hydroamination of Alkenes and Alkynes. Angew. Chem. Int. Ed. 2016, 55, 48-57. (b) Nguyen, K. D.; Park, B. Y.; Luong, T.; Sato, H.; Garza, V. J.; Krische, M. J. Science 2016, 354, aah5133. (c) Liu, R. Y.; Buchwald, S. L. CuH-Catalyzed Olefin Functionalization: From Hydroamination to Carbonyl Addition. Acc. Chem. Res. 2020, 53, 1229-1243. (d) Yang, Y.; Perry, I. B.; Lu, G.; Liu, P.; Buchwald, S. L. CopperCatalyzed Asymmetric Addition of Olefin-Derived Nucleophiles to Ketones. Science 2016, 353, 144-150. (e) Yang, Y.; Perry, I. B.; Buchwald, S. L. Copper-Catalyzed Enantioselective Addition of Styrene-Derived Nucleophiles to Imines Enabled by Ligand-Controlled Chemoselective Hydrocupration. J. Am. Chem. Soc. 2016, 138, 9787-9790. (f) Bandar, J. S.; Ascic, E.; Buchwald, S. L. Enantioselective $\mathrm{CuH}$-Catalyzed Reductive Coupling of Aryl Alkenes and Activated Carboxylic Acids. J. Am. Chem. Soc. 2016, 138, 5821-5824. (g) Yuan, Y.; Zhang, X.; Qian, H.; Ma, S. Catalytic Enantioselective Allene-Anhydride Approach to $\beta, \gamma$-Unsaturated Enones Bearing an $\alpha$ All-Carbon-Quaternary Center. Chem. Sci. 2020, 11, 9115-9121. (h) Saxena, A.; Choi, B.; Lam, H. W. Enantioselective Copper-Catalyzed Reductive Coupling of Alkenylazaarenes with Ketones. J. Am. Chem. Soc. 2012, 134, 8428-8431. (i) Tsai, E. Y.; Liu, R. Y.; Yang, Y.; Buchwald, S. L. A Regio- and Enantioselective CuH-Catalyzed Ketone Allylation with Terminal Allenes. J. Am. Chem. Soc. 2018, 140, 2007-2011. (j) Li, K.; Shao, X.; Tseng, L.; Malcolmson, S. J. 2Azadienes as Reagents for Preparing Chiral Amines: Synthesis of 1,2Amino Tertiary Alcohols by Cu-Catalyzed Enantioselective Reductive Couplings with Ketones. J. Am. Chem. Soc. 2018, 140, 598-601. (k) Jang, W. J.; Yun, J. Copper-Catalyzed Tandem Hydrocupration and Diastereo- and Enantioselective Borylalkyl Addition to Aldehydes. Angew. Chem., Int. Ed. 2018, 57, 12116-12120. (1) Shao, X.; Li, K.; Malcolmson, S. J. Enantioselective Synthesis of anti-1,2Diamines by $\mathrm{Cu}-\mathrm{Catalyzed} \mathrm{Reductive} \mathrm{Couplings} \mathrm{of} \mathrm{Azadienes} \mathrm{with}$ Aldimines and Ketimines. J. Am. Chem. Soc. 2018, 140, 7083-7087.

(21) (a) Gui, Y.; Hu, N.; Chen, X.; Liao, L.; Ju, T.; Ye, J.; Zhang, Z.; Li, J.; Yu, D. Highly Regio- and Enantioselective Copper-
Catalyzed Reductive Hydroxymethylation of Styrenes and 1,3-Dienes with $\mathrm{CO}_{2}$. J. Am. Chem. Soc. 2017, 139, 17011-17014. (b) Chen, X.; Zhu, L.; Gui, Y.; Jing, K.; Jiang, Y.; Bo, Z.; Lan, Y.; Li, J.; Yu, D. Highly Selective and Catalytic Generation of Acyclic Quaternary Carbon Stereocenters via Functionalization of 1,3-Dienes with $\mathrm{CO}_{2} . J$. Am. Chem. Soc. 2019, 141, 18825-18835. (c) Qiu, J.; Gao, S.; Li, C.; Zhang, L.; Wang, Z.; Wang, X.; Ding, K. Construction of All-Carbon Chiral Quaternary Centers through $\mathrm{Cu}^{\mathrm{I}}$-Catalyzed Enantioselective Reductive Hydroxymethylation of 1,1-Disubstituted Allenes with $\mathrm{CO}_{2}$. Chem. Eur. J. 2019, 25, 13874-13878. (d) Li, W.; Chen, L.; Lin, Z.; Man, S.; Qin, X.; Lyu, Y.; Li, C.; Leng, G. Theoretical Characterization of Catalytically Active Species in Reductive Hydroxymethylation of Styrene with $\mathrm{CO}_{2}$ over a Bisphosphine-Ligated Copper Complex. Inorg. Chem. 2020, 59, 9667-9682. (e) Wang, M.; Jin, X.; Wang, X.; Xia, S.; Wang, Y.; Huang, S.; Li, Y.; He, L.; Ma, $\mathrm{X}$. Copper-Catalyzed and Proton-Directed Selective Hydroxymethylation of Alkynes with $\mathrm{CO}_{2}$. Angew. Chem., Int. Ed. 2021, 60, 3984-3988.

(22) Appella, D. H.; Moritani, Y.; Shintani, R.; Ferreira, E. M.; Buchwald, S. L. Asymmetric Conjugate Reduction of $\alpha, \beta$-Unsaturated Esters Using a Chiral Phosphine-Copper Catalyst. J. Am. Chem. Soc. 1999, 121, 9473-9474.

(23) Suess, A. M.; Uehling, M. R.; Kaminsky, W.; Lalic, G. Mechanism of Copper-Catalyzed Hydroalkylation of Alkynes: An Unexpected Role of Dinuclear Copper Complexes. J. Am. Chem. Soc. 2015, 137, 7747-7753.

(24) The only exception was the hydrolysis to give carboxylic acid 31, which was carried out after first isolating the corresponding ester in order to facilitate its purification.

(25) (a) Pascaud, X.; Honde C.; Le Gallou, B.; Chanoine, F.; Roman, F.; Bueno, L.; Junien, J. L. Effects of Fedotozine on Gastrointestinal Motility in Dogs: Mechanism of Action and Related Pharmocokinetics. J. Pharm. Pharmacol. 1990, 42, 546-552. (b) Hager, A.; Vrielink, N.; Hager, D.; Lefranc, J.; Trauner, D. Synthetic Approaches Towards Alkaloids Bearing $\alpha$-Tertiary Amines. Nat. Prod. Rep. 2016, 33, 491-522. (c) Bera, K.; Namboothiri, I. N. N. Asymmetric Synthesis of Quaternary $\alpha$-Amino Acids and Their Phosphonate Analogues. Asian J. Org. Chem. 2014, 3, 1234-1260.

(26) Ordóñez, M.; Cativiela, C. Stereoselective Synthesis of $\gamma$ Amino Acids. Tetrahedron: Asymmetry 2007, 18, 3-99.

(27) Guo, S.; Yang, J. C.; Buchwald, S. L. A Practical Electrophilic Nitrogen Source for the Synthesis of Chiral Primary Amines by Copper-Catalyzed Hydroamination. J. Am. Chem. Soc. 2018, 140, $15976-15984$.

(28) Cattaneo, M.; Bevilacqua, C.; Lecchi ,A.; Mannucci, P. M. In vitro and ex vivo Effects of Indobufen on Human Platelet Aggregation, the Release Reaction and Thromboxane $\mathrm{B}_{2}$ Production. Haemostasis 1987, 17, 293-300.

(29) (a) Cerletti, C.; Manarini, S.; Colombo, M.; Tavani, A. The (+)-Enantiomer Is Responsible for the Antiplatelet and AntiInflammatory Activity of $( \pm$ )-Indobufen. J. Pharm. Pharmacol. 1990, 42, 885-887. (b) Patrignani, P.; Volpi, D.; Ferrario, R.; Romanzini, L.; Somma, M. D.; Patrono, C. Effects of Racemic, S- and R-Indobufen on Cyclooxygenase and Lipoxygenase Activities in Human Whole Blood. Eur. J. Pharmacol. 1990, 191, 83-88. (c) Yao, Y. Righthanded Indobufen and Use for Preparing Medicament. CN 101270072 (A), Sep. 24, 2008.

(30) (a) Ye, Y.; Kevlishvili, I.; Feng, S.; Liu, P.; Buchwald, S. L. Highly Enantioselective Synthesis of Indazoles with a C3-Quaternary Chiral Center Using CuH Catalysis. J. Am. Chem. Soc. 2020, 142, 10550-10556. (b) Liu, R. Y.; Yang, Y.; Buchwald, S. L. Regiodivergent and Diastereoselective CuH-Catalyzed Allylation of Imines with Terminal Allenes. Angew. Chem., Int. Ed. 2016, 55, 14077-14080. 


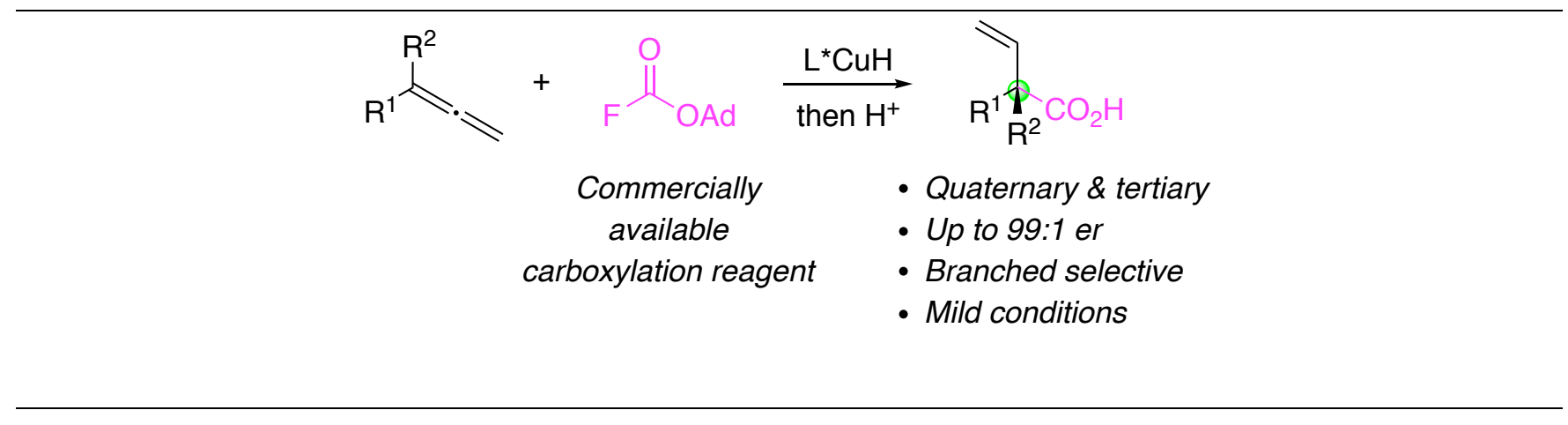

